\title{
Influence of atmospheric oxygen on hydrogen detection on Pd using Kelvin probe technique
}

\author{
Gabriela Schimo $^{1,2} \cdot$ Wolfgang Burgstaller ${ }^{1,3}$ - Achim Walter Hassel ${ }^{1,2,3}$ (I)
}

Received: 28 March 2017 / Revised: 25 July 2017 / Accepted: 27 July 2017 / Published online: 30 September 2017

(C) The Author(s) 2017. This article is an open access publication

\begin{abstract}
Influence of oxygen concentration in the measurement atmosphere on detection of hydrogen using Kelvin probe was studied. The studied material was a $100-\mu \mathrm{m}$-thick palladium foil, which was mounted in a 3D printed electrochemical flow cell. The used setup enables hydrogen loading with in-situ contact potential measurement of the hydrogen exit side of the Pd electrode. The hydrogen loading and unloading procedure, including insertion of different amounts of hydrogen into the Pd membrane and recording resulting values of contact potential difference, was performed at distinct oxygen concentrations ranging between 1 and $80 \mathrm{vol} \%$. An increasing amount of oxygen in the atmosphere surrounding the hydrogen-loaded Pd electrode resulted in an accelerated removal of hydrogen from the Pd. The kinetics of this reaction was studied based on Kelvin probe measurements, and a reaction mechanism is discussed.
\end{abstract}

Keywords Kelvin probe $\cdot$ Hydrogen detection $\cdot$ Palladium · Diffusion $\cdot$ Permeation $\cdot$ Atmospheric oxygen

Achim Walter Hassel

achimwalter.hassel@jku.at

1 Institute for Chemical Technology of Inorganic Materials, Johannes Kepler University Linz, Altenberger Str. 69, 4040 Linz, Austria

2 CEST Competence Centre for Electrochemical Surface Technology, Viktor Kaplan Str. 2, 2700 Wiener Neustadt, Austria

3 Christian Doppler Laboratory for Combinatorial Oxide Chemistry, at the Institute for Chemical Technology of Inorganic Materials, Johannes Kepler University Linz, Altenberger Str. 69, 4040 Linz, Austria

\section{Introduction}

Palladium is playing an essential role in hydrogen economy [1], which is due to the unprecedented properties of $\mathrm{Pd}$. Compared to other metals, it can easily absorb a large amount of hydrogen at standard conditions [2]. Hydrogen uptake into $\mathrm{Pd}$ is proceeding in a two-step mechanism with dissociation and adsorption of the hydrogen molecule on the metal surface as first step [3-5]. Hydrogen insertion can be also achieved electrochemically from aqueous electrolyte by application of a suitably cathodic potential as shown for Pd theoretically $[6,7]$ and practically in alkaline [8-13] and acidic electrolyte [14, 15]. The simplicity of hydrogen uptake makes $\mathrm{Pd}$ a promising candidate for hydrogen storage [16-19], for example as catalyst for hydrogen uptake and removal in other hydride forming metals [20]. Its properties enable also application as membrane for hydrogen purification [21-23]. Regarding the hydride formation of Pd, it is important to consider the $\mathrm{Pd}-\mathrm{H}$ phase diagram [24], which indicates the occurrence of two phases [25-27]: $\alpha-\mathrm{PdH}_{\mathrm{x}, \alpha}\left(x_{\alpha, \max }=0.015\right)$ and $\beta-\mathrm{PdH}_{\mathrm{x}, \beta}$ $\left(x_{\beta, \min }=0.607\right)$ are separated by a miscibility gap, characterized by the coexistence of both phases. Formation of the $\beta$ phase leads to change in several material properties such as decrease in electrical conductivity [28] and volume expansion of the Pd metal lattice [29]. On the one hand, this change in properties is the basis for hydrogen sensing [30-32], but on the other hand, it leads to drawbacks like hydrogen embrittlement [16, 33-35]. Based on the work of the Rohwerder group [36-39], Pd was introduced for sensing hydrogen in metals with Kelvin probe (KP) technique. Detection of hydrogen for example in steel has great importance for corrosion studies focusing hydrogen embrittlement-related damages [40-43]. The Kelvin probe method is capable of performing nondestructive surface characterization by means of contact potential difference (CPD) or Volta potential measurement. 
Therefore, KP studies are covering many research fields from the investigation of corrosion processes [44-49], visualization of hydrogen distribution in steel [37-39, 50-54] to reaction kinetics studies $[55,56]$.

The aim of this work is the investigation of Kelvin probe-based semi-quantitative detection of hydrogen in $\mathrm{Pd}$ and the influence of measurement conditions on the experiment. Part 1 of the present work [57] focuses on the influence of relative humidity on the hydrogen detection with $\mathrm{KP}$ and explains the fundamental aspects of hydrogen dependence of CPD. Building on these results, the influence of oxygen concentration in the measurement atmosphere is studied. By stepwise alternation of the oxygen concentration, the reaction kinetics of hydrogen removal from $\mathrm{Pd}$ involving oxygen as direct reaction partner in a water-forming reaction can be studied, which is of great importance for the evaluation of catalytic effects on reactions occurring on the Pd surface [58-63]. Additionally, application for hydrogen detection in other metal systems using $\mathrm{Pd}$ thin films is discussed.

\section{Experimental}

A $80 \times 10 \mathrm{~mm}$ sized, 0.1 -mm-thick palladium foil (Goodfellow, as rolled, 99.5\%) was cleaned ultrasonically with acetone, ethanol and deionized water, before mounting into the experimental setup, described elsewhere [57]. Description of the 3D-printed cell used for in situ hydrogen loading of the Pd foil during Kelvin probe measurements can be found elsewhere [13]. Deaerated $0.1 \mathrm{M} \mathrm{NaOH}$ electrolyte solution was pumped with a constant flow rate of $75 \mathrm{ml} \mathrm{min}^{-1}$ through the flow cell.

All KP measurements were performed with an in-house modified system with essential parts from Wicinski \& Wicinski GbR, utilizing a 300- $\mu$ m-thick $\mathrm{Cr}-\mathrm{Ni}$ tip, probing the surface in a distance of $110 \mu \mathrm{m}$. The KP sample chamber atmosphere was varied in terms of oxygen content, whereas relative humidity was kept constant at a low level $(4 \% \mathrm{rH})$ at a temperature of $22.3^{\circ} \mathrm{C}$. In order to enable comparison to electrochemical potentials, the system was calibrated before measurement by probing an electrochemical system with known potential, which was in this case the liquid surface of a saturated $\mathrm{CuSO}_{4}$ solution provided in a $\mathrm{Cu}$ crucible [44].

Electrochemical hydrogen loading was performed with a three-electrode arrangement including a $\mathrm{Hg} /$ $\mathrm{HgO} / 0.1 \mathrm{M} \mathrm{NaOH}$ micro-reference electrode and a gold counter electrode. For studying dependency of the KP signal on hydrogen concentration, increasing amounts of hydrogen were loaded into the Pd by applying potentiostatic pulses at $-0.7 \mathrm{~V}$ versus standard hydrogen electrode (SHE) with durations of 5, 15, 30, $50,75,105,140$ and $180 \mathrm{~s}$. For all electrochemical tests, a potentiostat (CompactStat, Ivium Technologies, The Netherlands) was used, operating in floating ground mode.

For the investigation of the KP signal variation on steel as well as on Pd-coated steel, $75 \times 10 \times 1.06 \mathrm{~mm}^{3}$-sized pieces of Fe-0.04C-0.18Mn-0.01P-0.011S steel (wt\%) were used. Pd coatings were fabricated either by physical vapour deposition or by electrochemical deposition. Electrochemical deposition was carried out galvanostatically as proposed by Flis et al. [64] from a $0.8 \mathrm{~g} \mathrm{l}^{-1} \mathrm{PdCl}_{2}$ (pro synthesis, Merck) and $60 \mathrm{~g} \mathrm{l}^{-1} \mathrm{NaOH}$ (TitriPur, Merck) electrolyte solution at room temperature. The thermal deposition was performed in a custom-developed thermal evaporator from high purity Pd (99.95\%, Heimerle + Meule GmbH Pforzheim, Germany). Process details are reported elsewhere [31]. The thickness of the fabricated Pd layers was $90 \mathrm{~nm}$ in case of electrodeposition and $110 \mathrm{~nm}$ for thermal evaporation. Steel specimens were ground with $\mathrm{SiC}$-paper up to grit 4000 before KPmeasurement and Pd deposition.

\section{Results and discussion}

\section{Hydrogen measurement and oxygen influence}

In similar manner as potential stability was shown for Pd during variation of relative humidity [57], stability has to be proven for increase of oxygen concentration in the measuring atmosphere. Independence of $C P D$ from measurement conditions ensures reliable hydrogen quantification, as deviations in $C P D$ are, as a consequence, exclusively based on changes in the hydrogen concentration within the investigated material. Due to the noble character of Pd, the influence of Pd oxidation processes occurring on the surface, especially at higher oxygen concentrations, can be neglected. The variation of the oxygen concentration from almost 0 to $100 \mathrm{vol} \% \mathrm{O}_{2}$ leads to a slight increase of $C P D$ from 0.470 to $0.497 \mathrm{~V}$ (SHE) as shown in Fig. 1. The observed stepwise $C P D$ increase cannot be correlated to steps in oxygen concentration transient. However, oxygen adsorption might take place during this experiment leading to a rise in $C P D$. In case that this adsorption process is slow, a similar increasing trend in $C P D$, as the one observed, is conceivable, as oxygen adsorption proceeds too slowly as to react to an increase in oxygen concentration immediately. Therefore, an oxygen adsorption process should not be completely neglected.

At the highest adjusted oxygen concentration (96\%), the detection limit of the utilized oxygen sensor is reached leading to a displayed value of $100 \%$. In comparison to other metals or alloys like steel, Pd shows a very stable potential at various atmospheric conditions, concerning relative humidity [57] as 


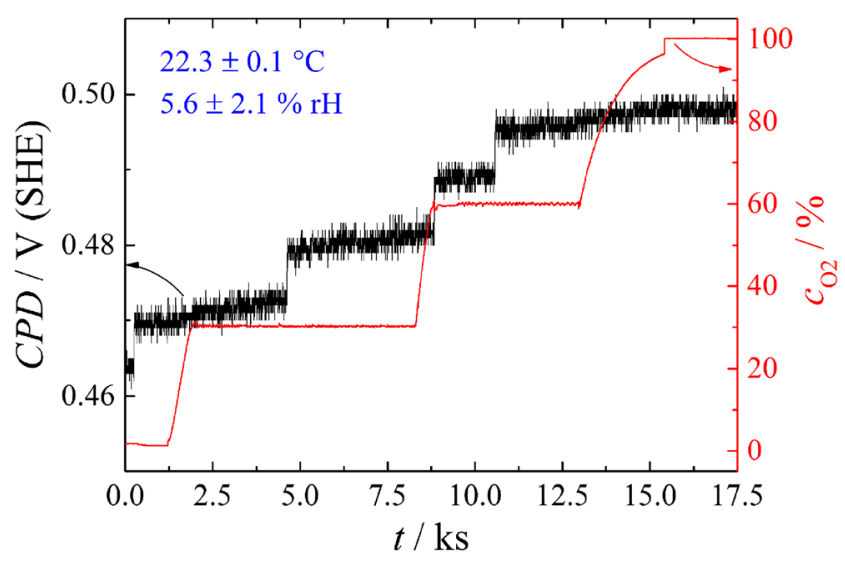

Fig. 1 Stability of $C P D$ measured on Pd in dependency of oxygen concentration in the Kelvin probe measurement chamber

well as oxygen concentration. Therefore, it is a well-suited material for hydrogen quantification as deviations in $C P D$ are only due to changes in concentration of hydrogen absorbed in the metal lattice.

In case of less noble metals and alloys, $C P D$ changes are extensively depending on the measurement conditions. A KP surface scan on a $5 \times 5$-mm-sized spot on ferritic steel was performed at distinct oxygen concentrations between 1 and $80 \mathrm{vol} \%$ to illustrate this aspect (Fig. 2). A rise in $C P D$ values can be observed for higher oxygen concentrations with largest and almost linear increase between 1 and 30 vol $\% \mathrm{O}_{2}$. The increase of $C P D$ measured on the steel surface can be due to oxidation processes according to the following equations:

$\mathrm{Fe} \rightarrow \mathrm{Fe}^{2+}+2 \mathrm{e}^{-}$

$\mathrm{Fe}^{2+} \rightarrow \mathrm{Fe}^{3+}+\mathrm{e}^{-}$

The $C P D$ dependence on the relative concentrations of $\mathrm{Fe} /$ $\mathrm{Fe}^{2+}$ and $\mathrm{Fe}^{2+} / \mathrm{Fe}^{3+}$ redox couples can be described via Nernst eq. $[37,50-52,65]$. As cathodic reaction, the oxygen reduction could be identified [49, 48, 47]. During atmospheric corrosion of steel, the separation of cathodic and anodic regions on the sample surface can be detected with KP as regions with lower and higher $C P D$ values respectively [66]. These regions could be also observed for the ferritic steel sample in this study but, due to the measurement conditions, only to a very low extent.

The variation of the potential due to atmospheric changes is in the range of $60-70 \mathrm{mV}$ for steel compared to approximately $30 \mathrm{mV}$ for Pd. Combined with the low probability of Pd to be oxidized at room temperature even at elevated oxygen content of the sample environment $[67,68]$, the advantages of using $\mathrm{Pd}$ for hydrogen detection are underlined.

For observation of $C P D$ changes due to different amounts of hydrogen electrochemically inserted into the sample, the Pd foil was hydrogen charged at a potential of $-0.7 \mathrm{~V}$ (SHE) for impulses with increasing duration from 5 to $180 \mathrm{~s}$. Each loading impulse is indicated by a sudden drop in $C P D$. The extent of this potential drop is dependent on the amount of hydrogen loaded into the sample. In between the loading pulses, hydrogen was allowed to effuse, which is indicated by a rise in potential towards the starting potential. This procedure was repeated for oxygen concentrations of $5,10,18,30,50$ and $80 \mathrm{vol} \%$, while the relative humidity was kept at a low level of 4\%. CPD transients recorded during hydrogen loading/ unloading cycles at oxygen concentrations of $5,10,18,30$, 50 and 80 vol\% are presented in Fig. 3a-f. The fluctuation of oxygen concentration was for each experiment below $5 \%$ of the adjusted value. Transients recorded at 1 vol. $\% \mathrm{O}_{2}$ for a freshly prepared Pd sample, which was not hydrogen charged before, as well as for hydrogen pre-charged Pd are not shown in this paper but are presented and discussed in Part I of the present work [57].

Results for all measurement conditions are depicted in Fig. 4 with $C P D$ minima observed due to hydrogen loading plotted versus logarithmic hydrogen concentration, which was calculated from integration of the current transients recorded during potentiostatic hydrogen loading $\left(c_{\mathrm{H} \text {,coulometric }}\right)$. It has to be emphasized that the calculated hydrogen concentrations inserted into the Pd membrane are approximated values as, amongst other aspects, the loss of hydrogen into the electrolyte was neglected but also the loss of hydrogen into the measurement atmosphere at the hydrogen detection side of the sample. This loss of hydrogen happens even before the amount of hydrogen, which is electrochemically loaded into the Pd membrane, can homogeneously spread over the entire thickness of the Pd sample. Therefore, a systematic deviation (towards lower hydrogen concentrations) of the approximated values from the real values can be assumed and has to be kept in mind. A precise determination of the hydrogen

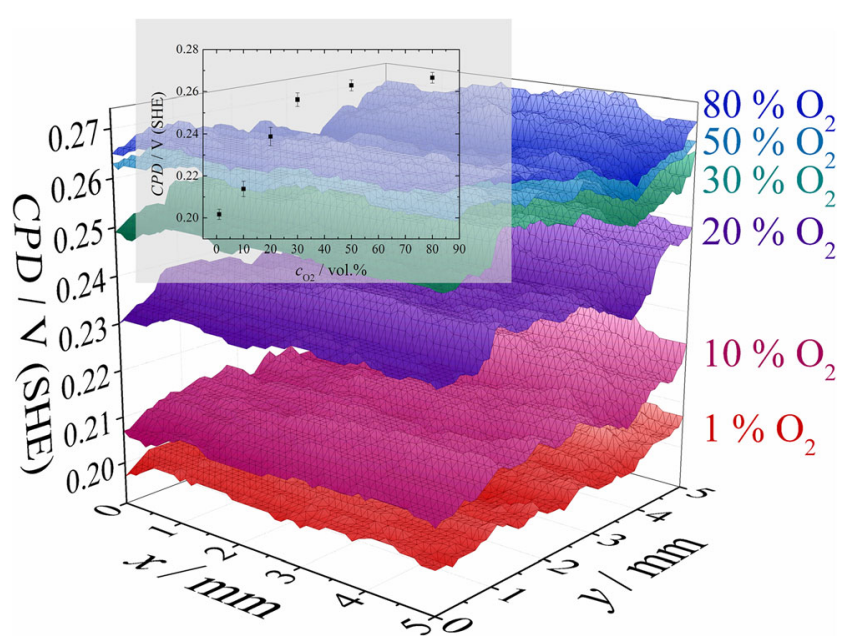

Fig. 2 Scanning Kelvin probe surface scan of a steel surface at various atmospheric oxygen concentrations and averaged values and error bars depicting standard deviation resulting from surface scans of $C P D$ (inset) 

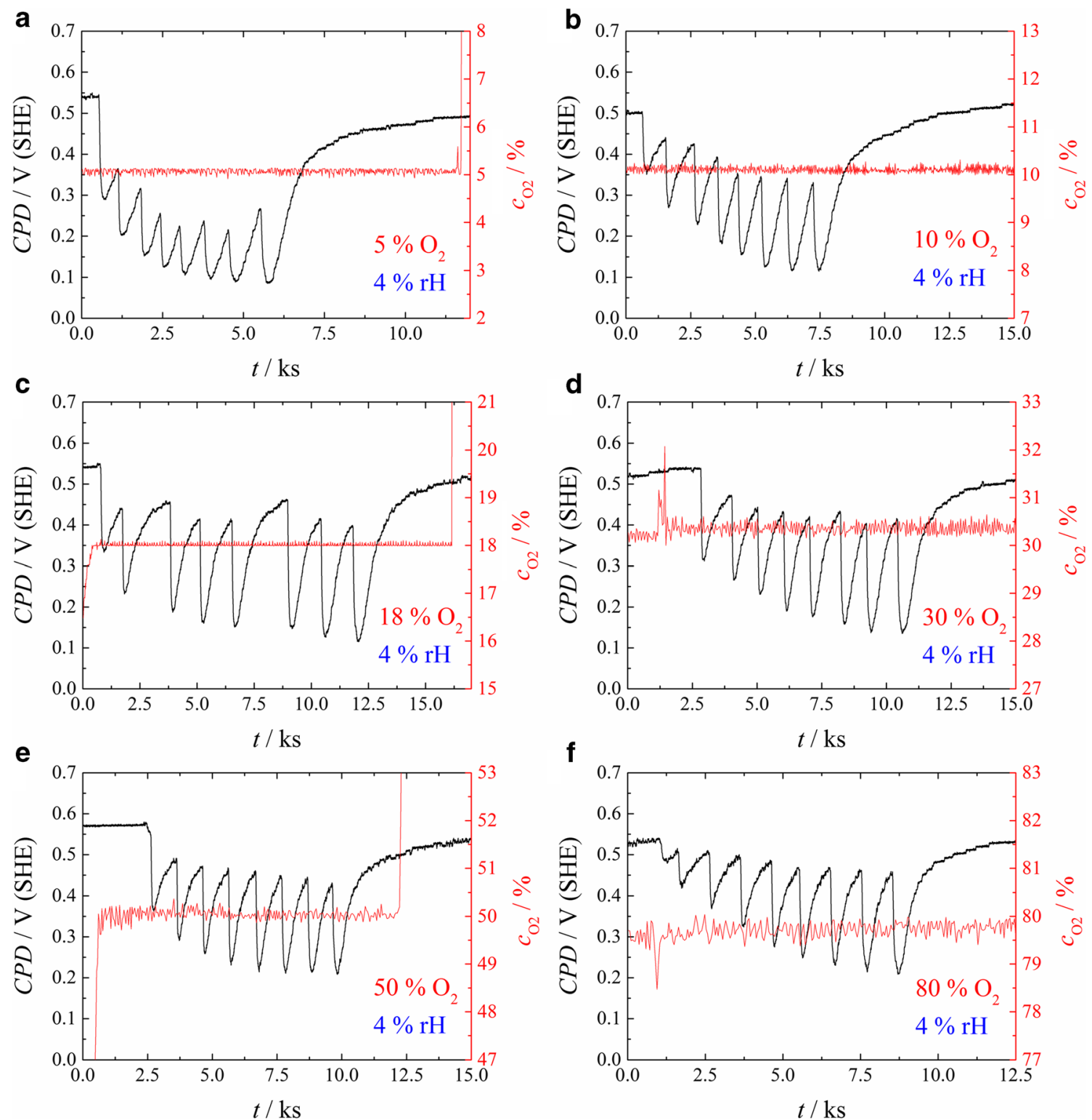

Fig. $3 C P D$ transients measured on hydrogen pre-charged samples during hydrogen loading and unloading impulses at different atmospheric oxygen concentrations and low humidity $(4 \% \mathrm{rH})$

concentrations reached at the hydrogen exit side probed by the KP can only be obtained via numerical simulation, which is beyond the scope of this work. Therefore, the approximated concentration values are used, enabling evaluation of measurement condition influence on this semi-quantitative approach of hydrogen detection.

A linear regression of the data points was performed to obtain a linear function for each atmospheric condition. The resulting values for the slope $(s)$ and axis intercept $(A)$ as well as correlation coefficient, revealing the quality of the linear fit, are listed in Table 1. As already thoroughly discussed earlier, the freshly prepared Pd specimen shows remarkable differences in behaviour compared to the measurement, which were performed consecutively on the same sample, which was therefore hydrogen pre-charged. Except for the curves measured at the lowest adjusted oxygen concentration of $1 \%$, a general shift of absolute $C P D$ values can be observed with curves shifted towards higher potentials at higher oxygen concentrations. Compared to the curves obtained at increasing relative humidity, the variation of oxygen concentration has a minor effect on the correlation coefficient, which is in each case well above 0.9 , and therefore on the quality of the linear fit. Thus, hydrogen detection can be performed with consistent quality at any oxygen concentration in the measurement atmosphere.

Surprisingly, slopes of the linear fitting curves vary over a wide range, more precisely from -0.074 to $-0.212 \mathrm{~V}$ per decade, except for the freshly prepared Pd (1), which exhibits 


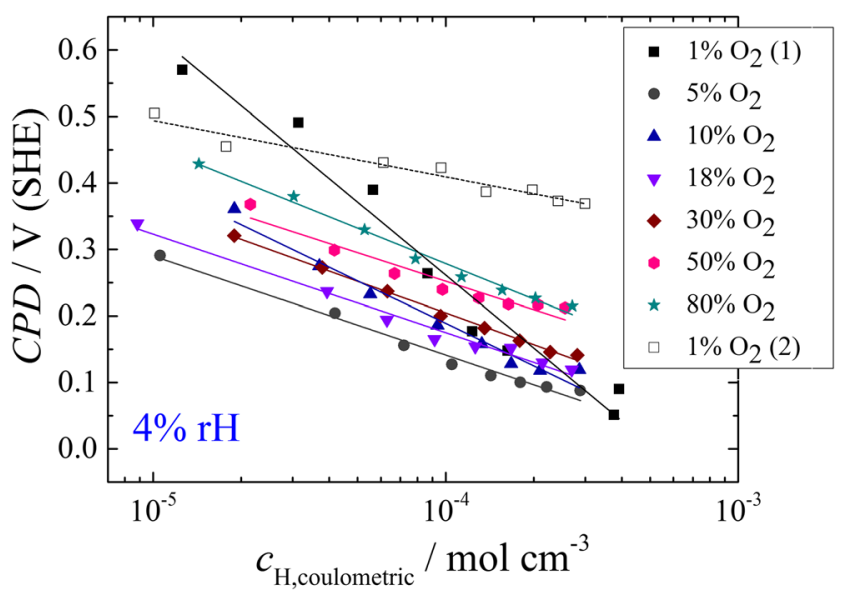

Fig. 4 Dependency of $C P D$ minima on coulometrically determined hydrogen concentration $\left(c_{\mathrm{H} \text {,coulometric }} / \mathrm{mol} \mathrm{cm}^{-3}\right)$ in the Pd sample, measured at different oxygen concentrations in the measurement chamber. Solid lines represent results from the linear regression of data points. Data points labelled with black square $\left(1 \% \mathrm{O}_{2}(1)\right)$ represent results for freshly prepared Pd sample [57]. All other values were obtained in consecutive measurements on the same Pd specimen

a slope of $-0.365 \mathrm{~V}$ per decade. Considering the theoretically expected slope of $-0.059 \mathrm{~V}$ per decade, which is derived from Nernst equation [37], the increase of oxygen concentration with simultaneously low levels of relative humidity leads to a greater deviation from the theoretical behaviour. Overview over the slopes during variation of relative humidity, presented in an earlier work [57], and during variation of oxygen concentration is shown in Fig. 5. With an average value of $-0.154 \mathrm{~V}$ per decade, slopes of linear fits obtained at higher oxygen concentrations are generally larger compared to those measured at increased levels of relative humidity, which are closer to a Nernstian behaviour. Low levels of humidity cause decrease of thickness of the surficial water layer. As proton concentration within this water layer should affect the electrode potential and therefore the measured $C P D$, volume changes of this layer are influencing the slope of the measurement curves. Deviations from Nernstian behaviour are reported in literature [36] and were due to the varying applicability of concentrations instead of activities of regarded oxidized and reduced species in the calculation of the electrode potential via Nernst equation. Regarding the deviation from the expected slope of $-0.059 \mathrm{~V}$ at oxygen concentrations above $1-5 \mathrm{vol} \%$ and simultaneously low levels of relative humidity, also an interaction of oxygen from the atmosphere and hydrogen on the Pd surface has to be considered. Further increase of the relative humidity above $5 \%$ has a minor influence on the slope, similarly as the increase of oxygen concentration above $5 \%$ cause negligible variation of the slope. Remarkably, the slope of the linear regression measured at $4 \% \mathrm{rH}$ and $1 \mathrm{vol} \%$ oxygen concentration deviates strongly from all other curves. This issue has already been raised [57] and could be due to an irreversible change of the sample during the first hydrogen loading cycle. This aspect is especially important for use of Pd-based hydrogen detection on other metal samples, like steel. Those samples have to be coated with palladium in order to enable hydrogen quantification based on the hydrogen concentration-dependent potential of Pd. Pd coatings can be realized by various methods like electrodeposition or physical vapour deposition (PVD) [31]. The deposition method determines the subsequent calibration routine as deposition methods can be divided into methods, which are characterized by a co-deposition of hydrogen and fabrication routes that ensure a hydrogen-free film. Electrodeposition usually comprises the co-deposition of hydrogen into the deposited palladium layer [69]. Electroless deposition can be also accompanied by hydrogen formation [70]. In contrast to these two methods, which both include the (electro-) chemical reduction of Pd ions, thermal evaporation is solely based on physical processes. Hydrogen insertion during preparation of the Pd thin film can be therefore excluded by deposition via PVD methods. With regard to the previously discussed differences in the $C P D$ dependence on hydrogen concentration observed for the fresh $\mathrm{Pd}$ and the re-used Pd membrane, thermally evaporated Pd films should exhibit a higher initial $C P D$ than electrochemically deposited films, which incorporated hydrogen during fabrication. In order to investigate this aspect, $C P D$ measurements were performed on two Pd films both with approximately $100 \mathrm{~nm}$ thickness, one obtained by electrodeposition and the other one by thermal evaporation. The resulting CPD measurements (not shown graphically) confirm this assumption: Line scans of $1 \mathrm{~cm}$ length over the surface of a thermally evaporated Pd thin film reveal an average $C P D$ of $0.593 \pm 0.004 \mathrm{~V}$ (SHE) compared to $0.553 \pm 0.009 \mathrm{~V}$ (SHE) measured for an electrochemically deposited thin film. Both line scans were performed at $2 \%$ relative humidity and $1 \%$ oxygen concentration.

Table 1 Linear regression results for measuring semi-quantitatively hydrogen concentration at varied atmospheric oxygen concentration $\left(c_{\mathrm{O} 2}\right)$ obtained by linear regression of measurement values presented in Fig. 4

\begin{tabular}{lll}
\hline$c_{\mathrm{O} 2}(\%)$ & Slope $_{\mathrm{V}}$ decade $^{-1}$ & Correlation coefficient $\left(\mathrm{R}^{2}\right)$ \\
\hline $1(1)$ & -0.365 & 0.9532 \\
$1(2)$ & -0.074 & 0.9629 \\
5 & -0.149 & 0.9816 \\
10 & -0.212 & 0.9666 \\
18 & -0.148 & 0.9793 \\
30 & -0.158 & 0.9949 \\
50 & -0.142 & 0.9225 \\
80 & -0.177 & 0.9855 \\
\hline
\end{tabular}




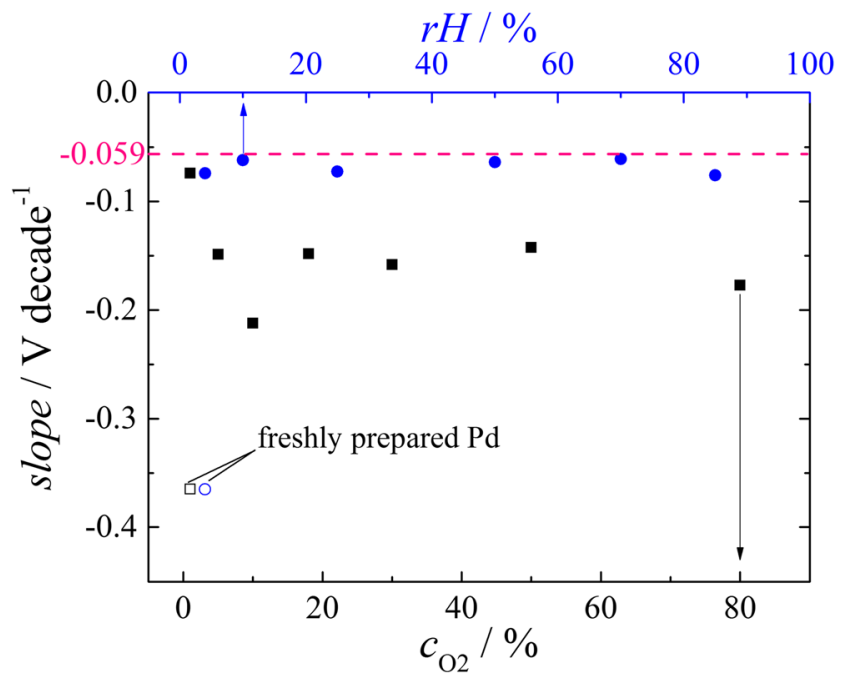

Fig. 5 Influence of relative humidity blue circle [57] and oxygen concentration black square in the KP measurement chamber on the slopes of the calculated linear regression, representing correlation of $C P D$ signal with the amount of hydrogen absorbed in $\mathrm{Pd}$

\section{Interaction of $\mathrm{PdH}_{\mathrm{x}}$ with atmospheric oxygen}

In contrast to an elevated relative humidity, which is only affecting the thickness of the water layer on the sample surface, oxygen concentration increase means a rise in concentration of a potential reaction partner for absorbed and adsorbed hydrogen.

Several studies have been published concerning the $\mathrm{Pd}-\mathrm{H}$ interaction, also in presence of oxygen. Hydrogen absorption was shown to be an exothermic reaction, in contrast to desorption, which is generally an endothermic process [71]. KP measurements performed by Lundström et al. showed that during the desorption process of hydrogen from Pd, a quasiequilibrium between surface and subsurface hydrogen forms (Eq. (3)) [56]. It was experimentally proven for the waterforming reaction on Pd that both components react in the adsorbed state [58-62].

The following reactions are supposed to occur on the Pd surface:

$$
\begin{aligned}
& \mathrm{H}_{\mathrm{ad}} \rightleftarrows \mathrm{H}_{\mathrm{ab}} \\
& 2 \mathrm{H}_{\mathrm{ad}} \rightleftarrows \mathrm{H}_{2}(\mathrm{~g}) \\
& \frac{1}{2} \mathrm{O}_{2}(\mathrm{~g}) \rightarrow \mathrm{O}_{a d} \\
& \mathrm{O}_{\mathrm{ad}}+\mathrm{H}_{\mathrm{ad}} \rightleftarrows \mathrm{OH}_{\mathrm{ad}} \\
& \mathrm{OH}_{\mathrm{ad}}+\mathrm{H}_{\mathrm{ad}} \rightarrow \mathrm{H}_{2} \mathrm{O}
\end{aligned}
$$

Concerning Eq. (5), the desorption of molecular oxygen from the Pd surface is unlikely to occur below $400{ }^{\circ} \mathrm{C}$, as reported based on thermal desorption spectroscopic results by Weissman-Wenocur et al. [62]. Oxygen, which is adsorbing on the Pd surface is therefore only consumed by a reaction with $\mathrm{H}_{\mathrm{ad}}$ forming $\mathrm{OH}_{\mathrm{ad}}$ and subsequently water (Eq. (6-7)).

Besides the reactions mentioned above, an electrochemical pathway of water formation via the oxygen reduction reaction (ORR) is also possible. Nørskov et al. [72] discussed the associative as well as the dissociative mechanism for ORR on Pt and other metals. The overall ORR can be described as

$\frac{1}{2} \mathrm{O}_{2}+2 \mathrm{H}^{+}+e^{-} \rightarrow \mathrm{H}_{2} \mathrm{O}$

The dissociative mechanism involves the dissociative adsorption of oxygen whereas the associative mechanism proceeds via adsorption of oxygen molecules forming peroxy intermediates. Whether the dissociative mechanism or the associative mechanism predominates is depending on the metal and other parameters such as the oxygen coverage [72].

The reaction rate $v$ of the hydrogen removal can be described in general form as follows:

$v=\frac{d c_{\mathrm{H}, \mathrm{ab}}}{d t}=k c_{\mathrm{O} 2}^{c} c_{\mathrm{H}, \mathrm{ab}}^{d}$

with $k$ as reaction rate constant and $c$ as the concentration of the involved species with their rate coefficients $(c$ and $d$ ) indicating the partial reaction orders.

For a given oxygen concentration in the atmosphere, the oxygen concentration can be assumed constant due to the fast diffusion. For this resulting constant oxygen concentration, the reaction order with respect to hydrogen can be described with the following equation:

$\ln v=k^{\prime}+d \ln c_{\mathrm{H}, \mathrm{ab}}$

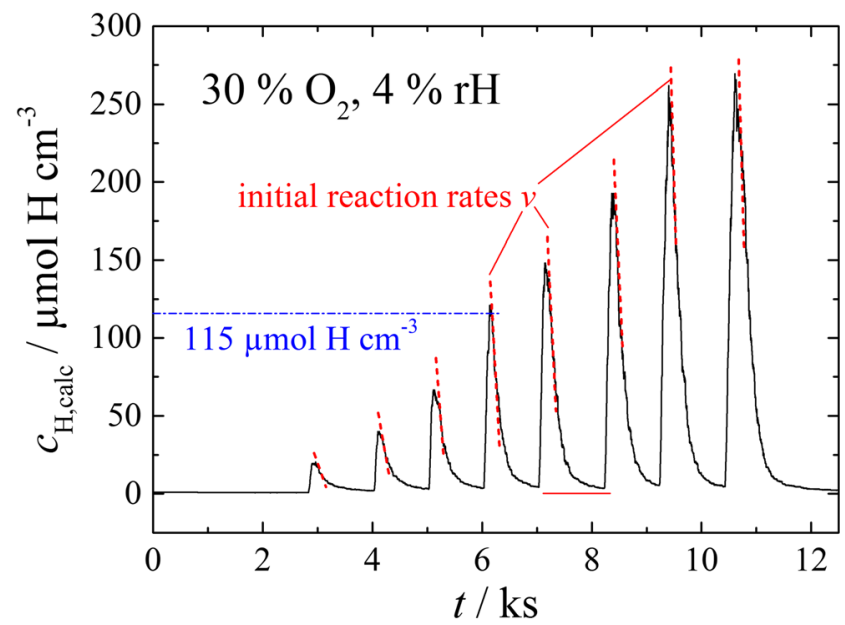

Fig. 6 Calculated (based on results from Table 1) transient of approximated hydrogen concentration absorbed in the sample $\left(c_{\mathrm{H}, \mathrm{calc}}\right)$ during consecutive hydrogen loading and unloading pulses for climatic condition of $30 \% \mathrm{O}_{2}$ and $4 \%$ relative humidity. Dashed lines represent evaluation of initial reaction rates for investigation of reaction kinetics of hydrogen removal from the sample 


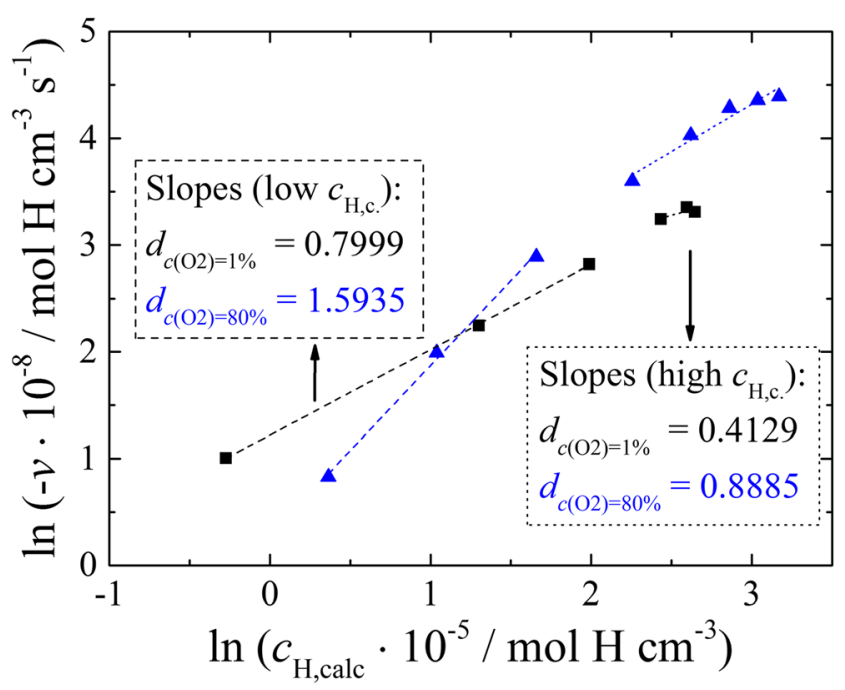

Fig. 7 Reaction rates of the hydrogen removal process $(v)$ in dependency of the calculated concentration of hydrogen in the Pd sample $\left(c_{\mathrm{H} \text {,calc }}\right)$ in double-logarithmic representation. Two datasets at constant oxygen concentrations of 1 and $80 \%$, representing the highest and lowest oxygen contents are shown including linear regression results

For the evaluation of the interaction of oxygen and absorbed/adsorbed $\mathrm{H}$ on the hydrogen-loaded Pd surface, hydrogen concentration transients were calculated based on the previously described linear regression results. One representative transient obtained by this method is presented in Fig. 6, depicting the transient at $30 \mathrm{vol} \% \mathrm{O}_{2}$ during the consecutive hydrogen loading and unloading steps. Hydrogen concentration within the sample is increased during hydrogen-loading pulses and subsequently decreased due to hydrogen removal from the sample. The steepness of the concentration transient during this unloading step gives information about the effusion rate of hydrogen.

Depending on the kinetics of the involved reaction, leading to a hydrogen removal, as well as on the reaction parameters, e.g. oxygen partial pressure and concentration of $\mathrm{H}$ in the $\mathrm{Pd}$ sample, the rate-determining reaction of hydrogen removal might change. In order to gain insight into the reaction mechanism of the hydrogen removal reaction in the studied case, initial reaction rates were evaluated from $c_{\mathrm{H} \text {,calc }}$ transients during hydrogen removal impulses. As oxygen concentration is thought to be influencing the hydrogen removal, the two extreme cases with highest ( $80 \mathrm{vol} \%$ ) and lowest ( 1 vol\%) oxygen concentration were studied in detail. Initial reaction rates of these two measurement series are plotted in a doublelogarithmic form versus maximum concentration of $\mathrm{H}_{\text {calc }}$, reached in the respective loading interval (Fig. 7), for evaluation of the reaction order. Reaction rates of hydrogen removal are increasing with rising hydrogen concentration, as expected. Interestingly, the obtained data plots show two distinct regions: at higher hydrogen concentrations, the slope of the curves, obtained by linear regression, and therefore the apparent reaction rate tends to be lower and less influenced by the presence of oxygen compared to the region of lower hydrogen concentration. Reaction orders appear in a range between 1.59 and 0.4 and enable no clear determination of the real reaction mechanism. Nevertheless, these results suggest the overlapping of two different processes occurring simultaneously on the Pd surface.

For further evaluation of the reaction mechanism, a different approach is chosen. Based on the observation of two distinct regions in the calculation of initial reaction rates, hydrogen concentration transients measured for the first and the last hydrogen removal interval are analysed. The reciprocal representation of the hydrogen concentration versus time is resulting in a linear relation indicating a second-order reaction (Fig. 8a, b).

This suggests that hydrogen removal is mainly based on hydrogen desorption, at least for the case of low oxygen concentrations, which is in turn resulting from the recombination of two hydrogen atoms adsorbed on the Pd surface. This observation is in good agreement with the literature [56, 63]. As mentioned before, the oxygen influence cannot be neglected
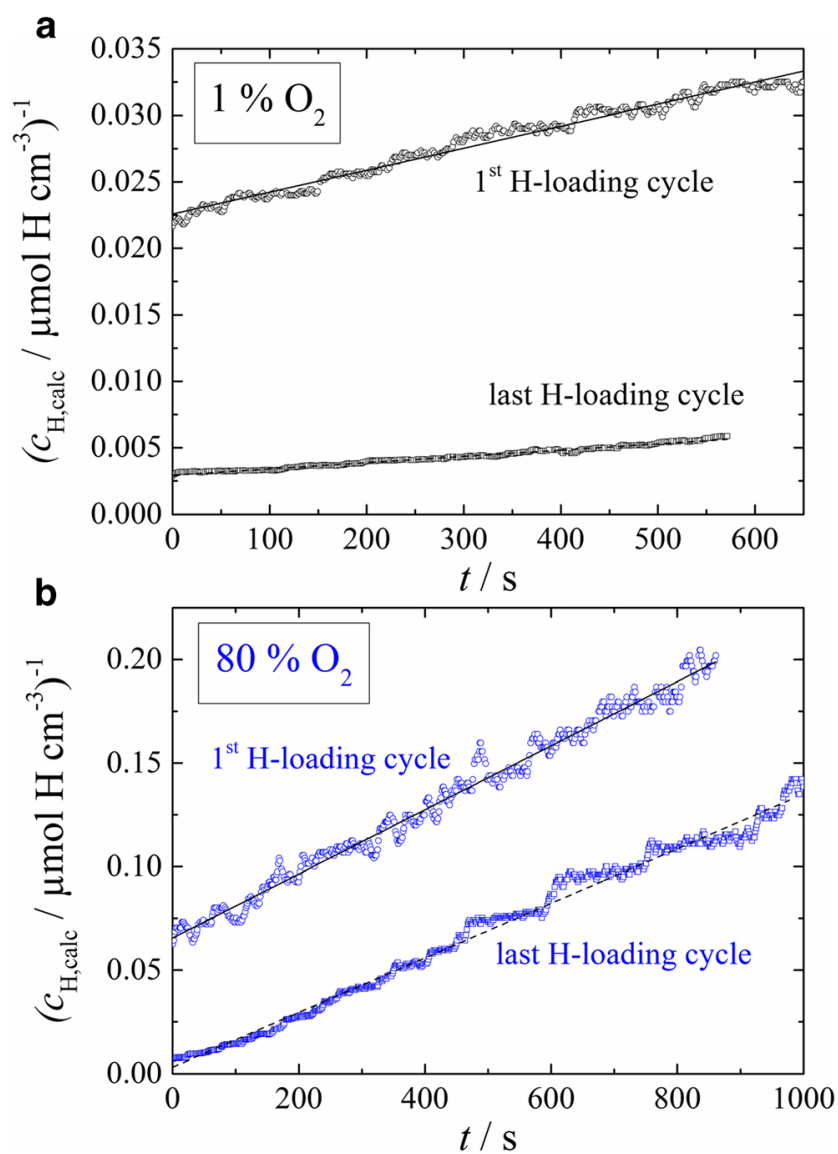

Fig. 8 Calculated hydrogen concentration plotted reciprocally versus time during the first and last hydrogen unloading impulse in calibration procedure at 1 and $80 \mathrm{vol} \%$ oxygen concentration in the measurement atmosphere 
as the oxygen concentration is obviously influencing the hydrogen removal rate. Higher reaction rates obtained for measurements at $80 \mathrm{vol} \%$ oxygen concentration clearly indicate an accelerated hydrogen removal and therefore a waterforming reaction mechanism. It was repeatedly reported that the formation of $\mathrm{OH}_{\mathrm{ad}}$ represents the rate-determining step in the water formation reaction [58-62].

For the determination of the reaction order with respect to oxygen, initial hydrogen concentrations have to be kept constant. Comparing the measured hydrogen concentration transients in terms of similar maximum hydrogen concentrations achieved during loading intervals, a value for $c_{\mathrm{H} \text {,calc }}$ of $0.115 \mu \mathrm{mol} \mathrm{H}$ per $\mathrm{cm}^{3}$ was found with small deviation $\left( \pm 0.02 \mu \mathrm{mol} \mathrm{cm}{ }^{-3}\right)$ in each measurement series. Therefore, the initial reaction rates of this particular unloading interval were used for the determination of the partial reaction order with respect to oxygen concentration. The results are shown in Fig. 9 and present an increase of the hydrogen removal rate in dependence of the oxygen partial pressure in the KP chamber.

Figure 9 reveals an apparent reaction order with respect to oxygen of 0.5 . This suggests that in this particular case, a dissociative adsorption of oxygen represents the rate-determining step. After the adsorption of oxygen, the reaction with hydrogen proceeds via $\mathrm{OH}_{\mathrm{ad}}$ formation and finally formation of water. Slow kinetics of oxygen adsorption was also discussed above in the "Hydrogen measurement and oxygen influence" section for hydrogen-free Pd (Fig. 1) and could contribute to a dissociative adsorption being the rate-determining step. Similar results for reaction order with respect to oxygen were found for ORR on $\mathrm{Pt}$ theoretically by density functional theory (DFT) calculations for low oxygen

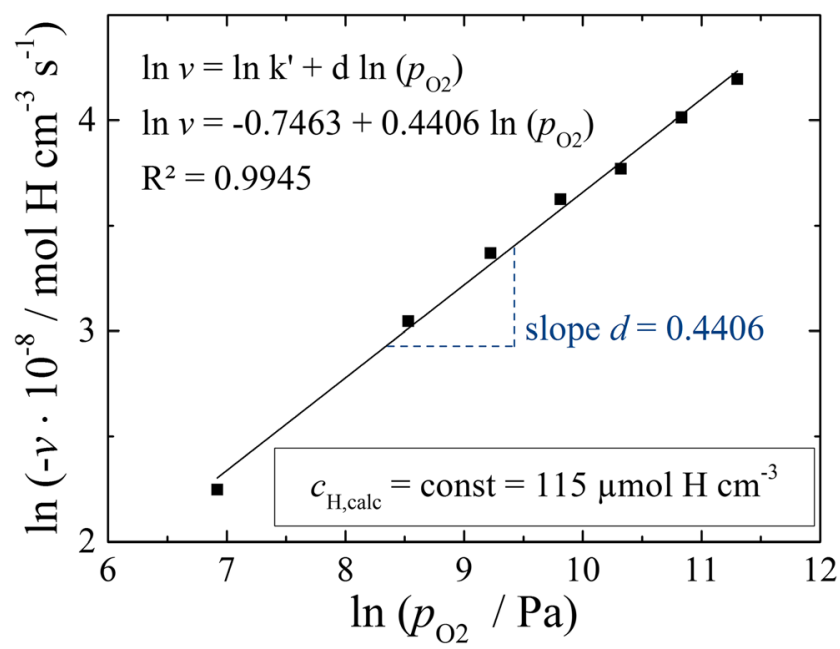

Fig. 9 Reaction rates of the hydrogen removal process $(v)$ at constant initial hydrogen concentration $\left(c_{\mathrm{H}, \text { calc }}\right)$ of $115 \pm 2 \mu \mathrm{mol} \mathrm{H}$ per $\mathrm{cm}^{3}$ absorbed in the Pd sample plotted versus the partial oxygen pressure $\left(p_{\mathrm{O} 2}\right)$ in the KP chamber, presented in a double-logarithmic form coverages [72] and experimentally for polymer exchange membrane fuel cells (PEMFC) [73-75].

From the kinetic investigations made in this work, it can be concluded that there are two reaction mechanisms that govern the hydrogen removal from the Pd membrane. At low oxygen concentrations (e.g. below $1 \mathrm{Vol} . \% \mathrm{O}_{2}$ ), the hydrogen removal is dominated by hydrogen recombination. By increasing the oxygen partial pressure in the chamber, the hydrogen removal is accelerated and the dominant reaction will be water formation.

\section{Conclusions}

The oxygen concentration is affecting the Kelvin probe determination of the contact potential difference $(C P D)$ of metals not only in terms of oxidation of the metal surface, as it was shown for a steel surface but also with respect to interaction with hydrogen absorbed and adsorbed in the metal. A procedure enabling semi-quantitative detection of hydrogen in $\mathrm{Pd}$ was set up, and influence of oxygen concentration in the measurement atmosphere was studied. Linear regression of measured $C P D$ minima during hydrogen loading versus coulometrically determined hydrogen concentration was performed to enable comparison with theoretical behaviour expected from Nernst equation. Obtained linear fits show similar slope but are generally higher than $-59 \mathrm{mV}$ per decade. Moreover, linear fits from measurement series measured at lower levels of humidity show higher deviation from the expected $-59 \mathrm{mV}$ per decade as those measured at higher levels of humidity. Differences for hydrogen-free and prior hydrogen-loaded and unloaded Pd were discussed with regard to Pd layer deposition methods to enable hydrogen detection in other metals. The adaption of the measurement and evaluation procedure to the Pd deposition route is of great importance. The present work can be used in the future as starting point for fully quantitative hydrogen detection with $\mathrm{KP}$ on $\mathrm{Pd}$, which requires simulation of the dynamic hydrogen concentration in the Pd membrane during hydrogen loading and unloading pulses.

From variation of oxygen concentrations within the KP measurement atmosphere, it could be found that higher oxygen concentrations lead to an accelerated hydrogen removal from Pd. Kinetic investigations revealed an overlapping of hydrogen desorption and water formation, partially via ORR on the Pd surface, which is promoted at higher oxygen concentrations.

Acknowledgments Open access funding provided by Johannes Kepler University Linz. The financial support within the Comet Programme given by the Austrian Government via FFG (Austrian Research Foundation Agency) and by the Government of Lower Austria and 
Upper Austria is gratefully acknowledged. The financial support by the Austrian Federal Ministry of Science, Research and Economy and the National Foundation for Research, Technology and Development through the Christian Doppler Laboratory for Combinatorial Oxide Chemistry (COMBOX) is gratefully acknowledged. The authors thank the voestalpine for the support as well as Prof. Andrei I. Mardare and Christian M. Siket for the many helpful discussions.

Open Access This article is distributed under the terms of the Creative Commons Attribution 4.0 International License (http:// creativecommons.org/licenses/by/4.0/), which permits unrestricted use, distribution, and reproduction in any medium, provided you give appropriate credit to the original author(s) and the source, provide a link to the Creative Commons license, and indicate if changes were made.

\section{References}

1. Adams BD, Chen A (2011) The role of palladium in a hydrogen economy. Mater Today 14:282-289

2. Jewell L, Davis B (2006) Review of absorption and adsorption in the hydrogen-palladium system. Appl Catal A 310:1-15

3. Lee J, Pyun S (2005) Anomalous behaviour of hydrogen extraction from hydride-forming metals and alloys under impermeable boundary conditions. Electrochim Acta 50:1777-1805

4. Mitsui T, Rose MK, Fomin E, Ogletree DF, Salmeron M (2003) Dissociative hydrogen adsorption on palladium requires aggregates of three or more vacancies. Nature 422:705-707

5. Nakatsuji H, Hada M (1985) Interaction of a hydrogen molecule with palladium. J Am Chem Soc 107:8264-8266

6. Gabrielli C, Grand PP, Lasia A, Perrot H (2004) Investigation of hydrogen adsorption-absorption into thin palladium films: I. Theory J Electrochem Soc 151:A1925

7. Zoltowski P (1999) Effects of self-induced mechanical stress in hydrogen sorption by metals, by EIS. Electrochim Acta 44:44154429

8. Devanathan MAV, Stachurski Z (1962) The adsorption and diffusion of electrolytic hydrogen in palladium. Proc Royal Soc A 270: 90-102

9. Yang T, Pyun S (1996) Hydrogen absorption and diffusion into and in palladium. Electrochim Acta 41:843-848

10. Yang T, Pyun S, Yoon Y (1997) Hydrogen transport through Pd electrode. Electrochim Acta 42:1701-1708

11. Lim C, Pyun S (1994) Impedance analysis of hydrogen absorption reaction on Pd membrane electrode in $0.1 \mathrm{M} \mathrm{LiOH}$ solution under permeable boundary conditions. Electrochim Acta 39:363-373

12. Martin MH, Lasia A (2008) Study of the hydrogen absorption in Pd in alkaline solution. Electrochim Acta 53:6317-6322

13. Schimo G, Burgstaller W, Hassel AW (2015) Potentiodynamic hydrogen permeation on palladium-Kelvin probe compared to $3 \mathrm{D}$ printed microelectrochemical cell. Electrochem Commun 60:208211

14. Zoltowski P, Makowska E (2001) Diffusion coefficient of hydrogen in $\alpha$-phase palladium and palladium-platinum alloy. Phys Chem Chem Phys 3:2935-2942

15. Gabrielli C, Grand PP, Lasia A, Perrot H (2004) Investigation of hydrogen adsorption and absorption in palladium thin films: II. Cyclic Voltammetry J Electrochem Soc 151:A1937

16. Narehood D, Kishore S, Goto H, Adair J, Nelson J, Gutierrez H, Eklund P (2009) X-ray diffraction and H-storage in ultra-small palladium particles. Int J Hydrog Energy 34:952-960

17. Züttel A, Sudan P, Mauron P, Kiyobayashi T, Emmenegger C, Schlapbach L (2002) Hydrogen storage in carbon nanostructures. Int J Hydrog Energy 27:203-212
18. Sakintuna B, Lamari-Darkrim F, Hirscher M (2007) Metal hydride materials for solid hydrogen storage. Int J Hydrog Energy 32:11211140

19. Schlapbach L, Züttel A (2001) Hydrogen-storage materials for mobile applications. Nature 414:353-358

20. Zaluski L, Zaluska A, Tessier P, Ström-Olsen JO, Schulz R (1995) Catalytic effect of Pd on hydrogen absorption in mechanically alloyed Mg2Ni, LaNi5 and FeTi. J Alloys Compd 217:295-300

21. Hatlevik Ø, Gade SK, Keeling MK, Thoen PM, Davidson AP, Way JD (2010) Palladium and palladium alloy membranes for hydrogen separation and production. Sep Purif Technol 73:59-64

22. Park ED, Lee D, Lee HC (2009) Recent progress in selective CO removal in a H2-rich stream. Catal Today 139:280-290

23. Li H, Xu H, Li W (2008) Study of $n$ value and $\alpha / \beta$ palladium hydride phase transition within the ultra-thin palladium composite membrane. J Membr Sci 324:44 49

24. Manchester FD, San-Martin A, Pitre JM (1994) The H-Pd (hydrogen-palladium) system. J Phase Equilibria 15:62-83

25. Vogel W, He W, Huang Q, Zou Z, Zhang X, Yang H (2010) Palladium nanoparticles "breathe" hydrogen; a surgical view with X-ray diffraction. Int J Hydrog Energy 35:8609-8620

26. Flanagan TB, Oates WA (1991) The palladium-hydrogen system. Annu Rev Mater Sci 21:269-304

27. Lewis F (1995) The palladium-hydrogen system. Int J Hydrog Energy 20:587-592

28. Baba K, Miyagawa U, Watanabe K, Sakamoto Y, Flanagan TB (1990) Electrical resistivity changes due to interstitial hydrogen in palladium-rich substitutional alloys. J Mater Sci 25:3910-3916

29. Feenstra R, Griessen R, de Groot DG Hydrogen induced lattice expansion and effective $\mathrm{H}-\mathrm{H}$ interaction in single phase PdHc. J Phys F: Met Phys 16:1933

30. Ghasemi S, Hosseini SR, Nabipour S, Asen P (2015) Palladium nanoparticles supported on graphene as an efficient electrocatalyst for hydrogen evolution reaction. Int J Hydrog Energy 40:1618416191

31. Walkner S, Schimo G, Mardare AI, Hassel AW (2015) Palladium thin films for hydrogen sensing in aqueous electrolytes. Phys Status Solidi A 212:1273-1280

32. Șennik E, Kılınç N, Öztürk ZZ (2010) Temperature-dependent H2 gas-sensing properties of fabricated Pd nanowires using highly oriented pyrolytic graphite. J Appl Phys 108:54317

33. Merzlikin SV, Wildau M, Steinhoff K, Hassel AW (2014) Prove of hydrogen formation through direct potential measurements in the rolling slit during cold rolling. Metall Res Technol 111:25-35

34. Cottis RA (2010) In: Richardson TA, Cottis RA, Shreir LL (eds) Hydrogen Embrittlement, 4th edn. Elsevier, Amsterdam

35. Feitosa J, da Cruz A, Souza AC, Duda FP (2015) Stress effects on hydrogen permeation through tubular multilayer membranes. Int $\mathrm{J}$ Hydrog Energy 40:17031-17037

36. Evers S, Rohwerder M (2012) The hydrogen electrode in the "dry". Electrochem Commun 24:85-88

37. Evers S, Senöz C, Rohwerder M (2013) Hydrogen detection in metals: a review and introduction of a Kelvin probe approach. Sci Technol Adv Mater 14:14201

38. Evers S, Senöz C, Rohwerder M (2013) Spatially resolved high sensitive measurement of hydrogen permeation by scanning Kelvin probe microscopy. Electrochim Acta 110:534-538

39. Senöz C, Evers S, Stratmann M, Rohwerder M (2011) Scanning Kelvin probe as a highly sensitive tool for detecting hydrogen permeation with high local resolution. Electrochem Commun 13: $1542-1545$

40. Akiyama E, Li S, Shinohara T, Zhang Z, Tsuzaki K (2011) Hydrogen entry into $\mathrm{Fe}$ and high strength steels under simulated atmospheric corrosion. Electrochim Acta 56:1799-1805

41. Pressouyre GM (1980) Trap theory of hydrogen embrittlement. Acta Metall 28:895-911 
42. Herlach D, Kottler C, Wider T, Maier K (2000) Hydrogen embrittlement of metals. Phys B 289-290:443-446

43. Djukic MB, Sijacki Zeravcic V, Bakic GM, Sedmak A, Rajicic B (2015) Hydrogen damage of steels. Eng Fail Anal 58:485-498

44. Rohwerder M, Turcu F (2007) High-resolution Kelvin probe microscopy in corrosion science. Electrochim Acta 53:290-299

45. Frankel GS, Stratmann M, Rohwerder M, Michalik A, Maier B, Dora J, Wicinski M (2007) Potential control under thin aqueous layers using a Kelvin probe. Corros Sci 49:2021-2036

46. Prosek T, Nazarov A, Bexell U, Thierry D, Serak J (2008) Corrosion mechanism of model zinc-magnesium alloys in atmospheric conditions. Corros Sci 50:2216-2231

47. Stratmann M, Streckel H (1990) On the atmospheric corrosion of metals which are covered with thin electrolyte layers-I. Verification of the experimental technique. Corros Sci 30:681-696

48. Stratmann M, Streckel H (1990) On the atmospheric corrosion of metals which are covered with thin electrolyte layers-II. Experimental results. Corros Sci 30:697-714

49. Stratmann M, Streckel H, Kim KT, Crockett S (1990) On the atmospheric corrosion of metals which are covered with thin electrolyte layers-III. The measurement of polarisation curves on metal surfaces which are covered by thin electrolyte layers. Corros Sci 30: $715-734$

50. Krasemann M, Streckel H, Hoffmann K, Grabke H, Stratmann M (1998) Passivity Breakdown and related processes. In: Natishan PM (ed) Detection of hydrogen ingress into iron oxide and iron oxy-hydroxide layers by the Kelvin probe. Proceedings of the symposium on Passivity and its breakdown. Electrochemical Society, Pennington, NJ

51. Williams G, McMurray HN, Newman RC (2013) Surface oxide reduction by hydrogen permeation through iron foil detected using a scanning Kelvin probe. Electrochem Commun 27:144-147

52. Schaller RF, Scully JR (2014) Measurement of effective hydrogen diffusivity using the scanning Kelvin probe. Electrochem Commun 40:42-44

53. Wang G, Yan Y, Yang X, Li J, Qiao L (2013) Investigation of hydrogen evolution and enrichment by scanning Kelvin probe force microscopy. Electrochem Commun 35:100-103

54. Schimo G, Burgstaller W, Hassel AW (2016) Rolling direction dependent diffusion coefficient of hydrogen in ferritic steel by SDCM charging and SKP probing. ISIJ Int 56:487-491

55. Söderberg D, Lundström I (1983) Competition between hydrogen and oxygen dissociation on palladium surfaces at atmospheric pressures. Solid State Commun 45:431-434

56. Lundström I, Söderberg D (1982) Isothermal hydrogen desorption from palladium films. Appl Surf Sci 10:506-522

57. Burgstaller W, Schimo G, Hassel AW (2017) Challenges in hydrogen quantification using Kelvin probe technique at different levels of relative humidity. J Solid State Electrochem 21:1785-1796
58. Demchenko DO, Sacha GM, Salmeron M, Wang L (2008) Interactions of oxygen and hydrogen on Pd(111) surface. Surf Sci 602:2552-2557

59. Mitsui T, Rose M, Fomin E, Ogletree D, Salmeron M (2002) Coadsorption and interactions of $\mathrm{O}$ and $\mathrm{H}$ on Pd(). Surf Sci 511: 259-266

60. Pauer G, Kratzer M, Winkler A (2005) Reaction and desorption kinetics of $\mathrm{H} 2$ and $\mathrm{H} 2 \mathrm{O}$ on activated and non-activated palladium surfaces. Vacuum 80:81-86

61. Engel T, Kuipers H (1979) A molecular-beam investigation of the reaction $\mathrm{H} 2+\mathrm{O} 2 \rightarrow \mathrm{H} 2 \mathrm{O}$ on $\mathrm{Pd}(111)$. Surf Sci 90:181-196

62. Weissman-Wenocur DL, Spicer WE (1983) Comparison between the catalytic activities of $\mathrm{Pd}(111)$ and $\mathrm{Pd}-\mathrm{Au}(111)$ for water synthesis. Surf Sci 133:499-515

63. Winkler A (2009) Adsorption, reaction and desorption of hydrogen on modified Pd(111) surfaces. Appl Surf Sci 256:1114-1119

64. Flis J (1999) Changes in hydrogen entry rate and in surface of iron during cathodic polarisation in alkaline solutions. Electrochim Acta 44:3989-3997

65. Nazarov AP, Marshakov AI, Rybkina AA (2015) Iron hydrogenation under atmospheric corrosion. Studies using a scanning vibrating microscope. Prot Met Phys Chem Surf 51:347-359

66. Nazarov A, Thierry D (2007) Application of Volta potential mapping to determine metal surface defects. Electrochim Acta 52: 7689-7696

67. Zheng G, Altman EI (2000) The oxidation of Pd(111). Surf Sci 462: $151-168$

68. Voogt EH, Mens A, Gijzeman O, Geus JW (1997) Adsorption of oxygen and surface oxide formation on $\operatorname{Pd}(111)$ and Pd foil studied with ellipsometry, LEED, AES and XPS. Surf Sci 373:210-220

69. Abys JA (2010) Palladium Electroplating. In: Schlesinger M Paunovic M (ed) Modern Electroplating, 5th ed. Wiley, Hoboken, N.J

70. Mallory GO, Hajdu JB (1990) Electroless plating. American Electroplaters and Surface Finishers Society, Orlando

71. Flanagan TB, Luo W, Clewley JD (1991) Calorimetric enthalpies of absorption and desorption of protium and deuterium by palladium. J Less Common Metal 172-174:42-55

72. Norskov JK, Rossmeisl J, Logadottir A, Lindqvist L, Kitchin JR, Bligaard T, Jónsson H (2004) Origin of the overpotential for oxygen reduction at a fuel-cell cathode. J Phys Chem B 108:17886-17892

73. Xu H, Song Y, Russell Kunz H, Fenton JM (2005) Effect of elevated temperature and reduced relative humidity on ORR kinetics for PEM fuel cells. J Electrochem Soc 152:A1828-A1836

74. Neyerlin KC, Gu W, Jorne J, Gasteiger HA (2006) Determination of catalyst unique parameters for oxygen reduction reaction in a PEMFC. J Electrochem Soc 153:A1955-A1963

75. Takahashi I, Kocha SS (2010) Examination of the activity and durability of PEMFC catalysts in liquid electrolytes. J Power Sources 195:6312-6322 